\title{
Synthesis of titanium carbide from the rutile concentrate by low temperature plasma
}

\author{
Evgeny Kuz'michev ${ }^{1 *}$ and Sergey Nikolenko ${ }^{2}$ \\ ${ }^{1}$ Far Eastern State Transport University, Khabarovsk, Russia. \\ ${ }^{2}$ Institute of Materials Science, Khabarovsk Scientific Center, Far Eastern Branch, Russian Academy \\ of Sciences, Khabarovsk, Russia.
}

\begin{abstract}
As a result of the synthesis of titanium-containing mineral raw materials (rutile concentrate), using high-density energies, the metal titanium and titanium carbide were produced. The article presents the results of experiments on the possibility of using high-density energies for the synthesis of functional materials for industrial use.
\end{abstract}

\section{Introduction}

The production and uses of ceramic materials for construction purposes, as well as the production of coatings using ceramic materials as basic components have developed rapidly in recent times. Compounds of metals and non-metals with boron, carbon and nitrogen serve as the basic components for these materials. Carbides, borides and nitrides are extensively used, especially carbides of refractory metals.

The industrial production of such compounds shows considerable promise and is conducted in the direction of its extraction from metal oxides by synthesis or mechanical diffusion. However, the use of a multicomponent mineral raw material that contains titanium for the production of $\mathrm{TiC}$ compounds is not possible without additional processing steps. In short, it is necessary to pay considerable attention to the preparation of titanium oxide and to the purification, leaching and precipitation of the resultant solutions, etc. Titanium-containing components are byproducts of the mining of various ores and their extraction is a significant problem. So-called after extraction "tails" (ore waste) from ore mining and processing enterprises are accumulated and then they are partially used in metallurgical production and welding processes or exported to Asia.

Alternative methods of chemical processing include high-temperature and plasmachemical synthesis.

Methods of titanium carbide production have long been known. For example, from the heating of powdered titanium oxide and soot in coal furnaces in a hydrogen atmosphere at $2250^{\circ} \mathrm{C}$ [1], but the productivity of this process is low. The method of mechanical alloying [2 - 4] requires the grinding of the initial charge, consisting of titanium powder and soot, in a planetary mill at room temperature. No free carbon atoms and soot are found in the final product, but the disadvantage of this method is the formation of a non-stoichiometric composition of titanium carbide. The self-propagating high-temperature synthesis (SHS)

*Corresponding author: accord@festu.khv.ru 
method concludes with the intimate mixing of powdered reactants and their sintering into briquettes that are used in the process of obtaining carbides at temperatures higher than $1600{ }^{\circ} \mathrm{C}[5-9]$.

The drawbacks of all these methods are low productivity, the use of rather complex equipment to create high temperatures and vacuum, and the use of "hermetic bombreactors", etc. In addition, in the majority of methods it is possible to use only sufficiently pure components, which implies their production from ore concentrates in earlier stages.

The task to be solved is to develop an alternative method for obtaining functional materials, titanium carbide and its compounds, using simple and sufficiently productive equipment that will cover domestic demand in the market, and use dumps in the form of a raw material base and possibly obtain new Ti-based compounds.

Thus, in our work we propose the method of obtaining titanium carbide from a multicomponent mineral oxide-containing raw material by applying high-density energy with the intensity $\mathrm{g}>10^{3}-10^{4} \mathrm{~W} / \mathrm{cm}^{2}$.

The initial content of titanium in the investigated material, the rutile concentrate, was about $75 \%$.

\section{Methods and materials}

In experiments aimed at obtaining a titanium-carbide compound $\left(\mathrm{TiC}_{\mathrm{x}}\right)$ we used a rutile concentrate and graphite powder.

The preparation of the mixture was carried out by the method of ranking. A portion of the mixture containing $70 \mathrm{wt} \%$ rutile concentrate and $30 \mathrm{wt} \%$ graphite powder was loaded into the planetary ball mill and ground for 20 minutes in ethanol. The reducing agent (carbidizer) was added to the charge with $10 \%$ excess. A charge $(\mathrm{P}+\mathrm{C})$ with a particle size of 70-100 $\mathrm{mm}$ was obtained as the output.

The charge $(\mathrm{P}+\mathrm{C})$ was supplied by the transport gas into the electrode channel through the channels of the plasma torch 5. We used industrial grade argon as the transport gas. The electrode had a tungsten tip, and the diameter of the passageway was about $0.8-1 \mathrm{~mm}$. A graphite nozzle was installed coaxially with the electrode. The nozzle was separated from the graphite by a dielectric, ceramic ring 2 (Fig. 1).

In the course of the gas flow through the channels of the plasma torch to the electrode and nozzle region, fine-dispersed particles of charge are transferred from the hopper. An electric discharge is created in the ionization region between the electrode and the nozzle of the plasma torch. In turn, the particles of the charge increase the conductivity of the gasdust flow, because $30 \%$ of the mixture consists of fine graphite powder.

As a result of simulating the gas motion in the chamber of the plasma torch by finite element methods and the nature of the synthesized material deposit, it was determined that the nature of the gas flow is represented by transient processes [10]. This led to the appearance of cyclic characteristics in the motion of particles. The particles move along toroidal trajectories with their subsequent ejection. So a particle can repeatedly cross a hot region of plasma with the gas flow. In contrast to the classical Gaussian character of the distribution of temperatures in the plasma plume over its entire length, the plasma flare is represented by a chaotic motion of the particles, which determines a uniform temperature distribution throughout the reactor volume. 


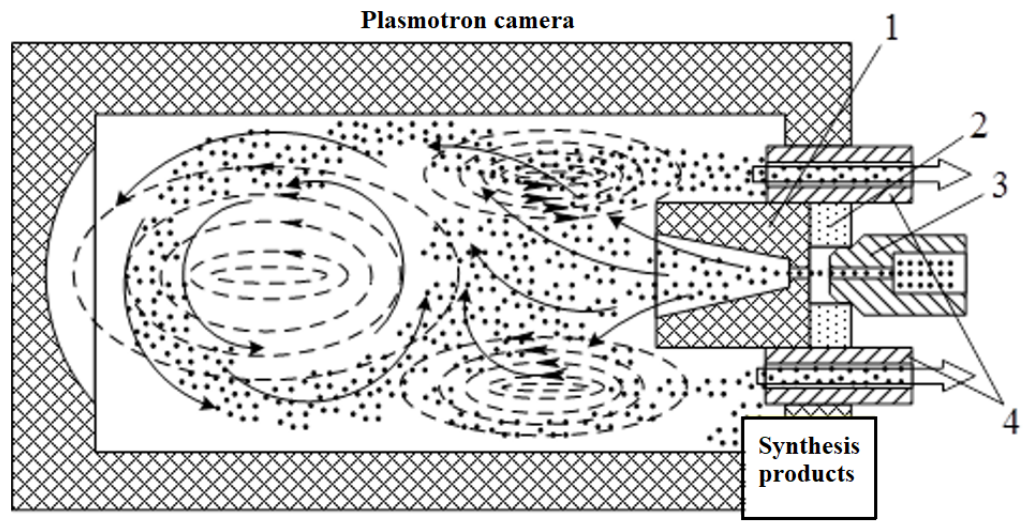

Fig 1. Scheme of the process of plasma-chemical synthesis: 1 - nozzle, 2 - dielectric ring, 3 electrode, 4 - gas-vapor phase and finely-dispersed discharge tubes.

The obtained samples were studied on an electron scanning microscope "VEGA 3 LMH" (TESCAN) equipped with an energy dispersive spectrometer "X-Max 80" (Oxford Instruments). Photographing samples and searching for micro-inclusions was carried out mainly with the regime of backward scattered electrons (BSE-detector). Using such a regime allows phases with a higher average atomic number to be reflected in sharper contrast compared with phases with a smaller average atomic number in the production of the image.

The phase analysis was also carried out using an electron transmission microscope ZEISS Libra-120 equipped with a HAADF detector and an energy $\Omega$-filter. Investigations were carried out in the modes of lumen, dark field, and electron micro-diffraction. Samples for transmission microscopy were prepared by electrolytic polishing and ionic etching.

The composition of the slag and the synthesized product were studied using a diffractometer "Dron 7" with a tube from Co on a K-line X-ray with a shooting speed of two degrees per minute.

At the end of the experiments we carried out a macro- and microanalysis of the samples obtained during the plasma-chemical synthesis and studied the slag and the precipitate of the vapor-drop phase.

The samples formed during plasma-chemical synthesis were represented by a hard fused material, which was easily ground in an agate mortar.

The results of the analysis showed the presence of the $\mathrm{TiC}$ phase as a result of the thermal action on the $\mathrm{P}+\mathrm{C}$ powder mixture.

In Fig. 2 (a) a photo of the samples of the plasma stream selected from the region of laminar motion with the least impact of turbulent flows is shown. Samples from this region were not affected by a constant magnetic field. The chemical composition of Fig. 2 (a) samples is shown in Table 1.

In Fig. 2 (b) we presented an image of the samples selected from areas that are more prone to turbulent motion of the plasma flow. In addition, on Fig. 2 (b) among the particles represented exclusively by the $\mathrm{TiC}$ compound, in the lighter region a sample under the spectrum 10 stands out. Collectively, such samples are often found in the form of condensate in the nozzle area and on the filter surface. In the sample under the spectrum 10 (Fig. 2 (b)) we also detected about 3 wt $\%$ of niobium (Nb). 
Table 1. Chemical composition of samples obtained as a result of plasma-chemical synthesis presented in Fig. 2 (a).

\begin{tabular}{|c|c|c|c|c|c|c|c|c|c|}
\hline $\begin{array}{c}\text { Specter } \\
\text { No. }\end{array}$ & $\mathrm{C}$ & $\mathrm{Mg}$ & $\mathrm{Al}$ & $\mathrm{Si}$ & $\mathrm{Fe}$ & $\mathrm{Ti}$ & $\mathrm{Mn}$ & Other, \% & Free C,\% \\
\hline 1 & 15.26 & - & 0.09 & - & - & 84.44 & - & 0.05 & 0.2 \\
\hline 2 & 19.35 & - & 0.18 & 0.01 & 0.009 & 80.24 & - & 0.008 & 0.203 \\
\hline 3 & 14.18 & - & 0.12 & - & - & 85.49 & - & 0.008 & 0.202 \\
\hline 4 & 17.22 & - & 0.11 & 0.01 & 0.007 & 82.44 & - & 0.008 & 0.205 \\
\hline 5 & 18.76 & - & 0.14 & 0.01 & 0.009 & 80.87 & - & 0.008 & 0.203 \\
\hline 6 & 11.54 & - & 0.1 & 0.03 & 0.008 & 88.11 & - & 0.002 & 0.21 \\
\hline
\end{tabular}
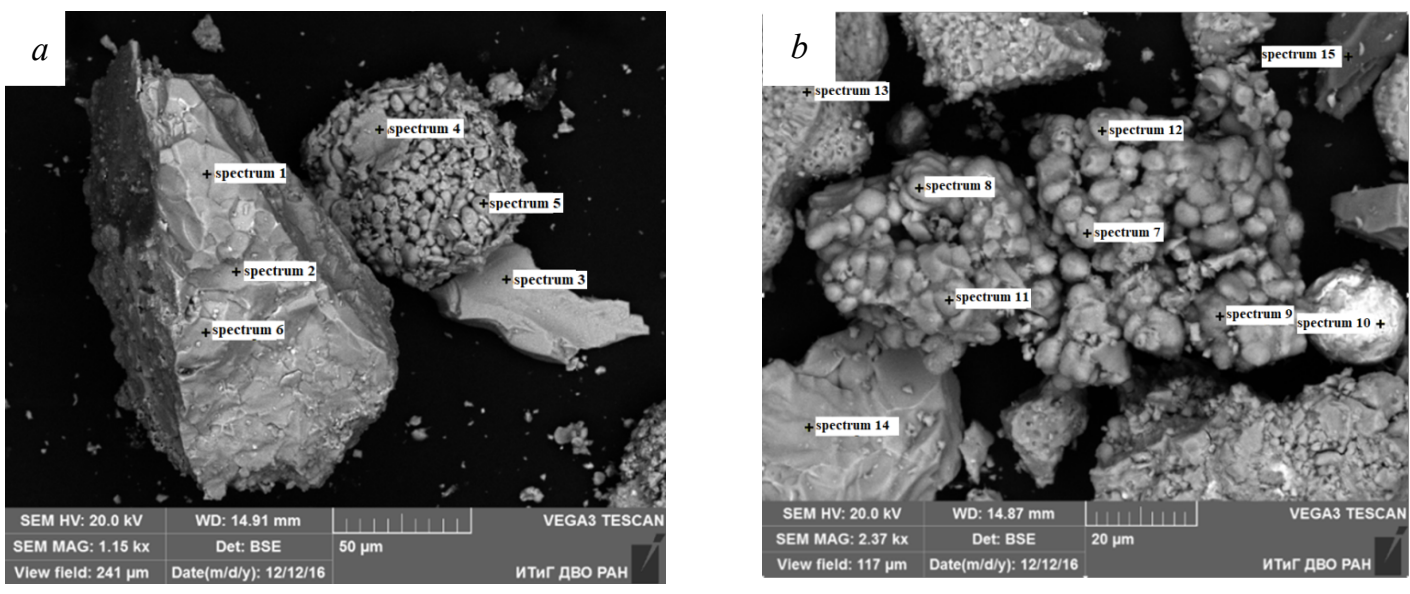

Fig. 2. The image of the sample in the reflected electrons selected from the laminar gas flow region at $50 \mu \mathrm{m}(\mathrm{a})$, and in the reflected electrons selected from the turbulent region at $20 \mu \mathrm{m}$ (b).

Chemical composition of Fig. 2 (b) samples is presented in Table 2.

Table 2. Chemical composition of samples obtained as a result of plasma-chemical synthesis presented in Fig. 2 (b).

\begin{tabular}{|c|c|c|c|c|c|c|c|c|c|}
\hline $\begin{array}{c}\text { Spectr } \\
\text { um No. }\end{array}$ & $\mathrm{C}$ & $\mathrm{Mg}$ & $\mathrm{Al}$ & $\mathrm{Si}$ & $\mathrm{Fe}$ & $\mathrm{Ti}$ & $\mathrm{Mn}$ & $\begin{array}{c}\text { Other, } \\
\%\end{array}$ & Free C,\% \\
\hline 7 & 16.26 & - & 0.08 & - & - & 83.47 & - & 0.004 & 0.186 \\
\hline 8 & 17.29 & - & 0.18 & 0.01 & 0.009 & 82.34 & - & 0.004 & 0.167 \\
\hline 9 & 13.12 & - & 0.12 & - & - & 86.58 & - & 0.004 & 0.176 \\
\hline 10 & 16.78 & 7 & 0.11 & 2 & 14 & 57.94 & 2 & 0.005 & 0.165 \\
\hline 11 & 17.35 & - & 0.14 & 0.01 & 0.009 & 82.27 & - & 0.003 & 0.218 \\
\hline 12 & 11.76 & - & 0.1 & 0.03 & 0.008 & 87.89 & - & 0.002 & 0.21 \\
\hline 13 & 12.31 & - & 0.1 & 0.03 & 0.008 & 87.34 & - & 0.002 & 0.21 \\
\hline 14 & 14.42 & - & 0.1 & 0.03 & 0.008 & 85.31 & - & 0.002 & 0.13 \\
\hline 15 & 15.24 & - & 0.08 & 0.03 & 0.005 & 84.51 & - & 0.002 & 0.133 \\
\hline
\end{tabular}

In Fig. 3 we present the spectrogram of Fig. $3(\mathrm{a}, \mathrm{b})$ samples. Insignificant impurities are found in the samples: Al $0.9-0.18 \mathrm{wt} \%, \mathrm{Si}-0.01 \mathrm{wt} \%, \mathrm{Fe}-0.009 \mathrm{wt} \%$, and free carbon up to $0.22 \%$. 
The carbon content in the titanium compound $\mathrm{TiC}$ was about $17 \mathrm{wt} \%$, and the $\mathrm{Ti}$ content was about $85 \mathrm{wt} \%$. The size of particles presented in Fig. 5 varies from $1 \mathrm{~nm}$ to 100 $\mu \mathrm{m}$. The particles are easily ground and resistant to various types of chemical reagent, which allowed the leaching procedure for separately occurring particles of iron, manganese, aluminum, etc. It also allowed us to evaluate the quality of material which resulted from leaching after washing and drying. The purity of the final product reached $89.5 \mathrm{wt} \%$ of the $\mathrm{TiC}$ phase and up to $10 \mathrm{wt} \%$ of the Ti phase.

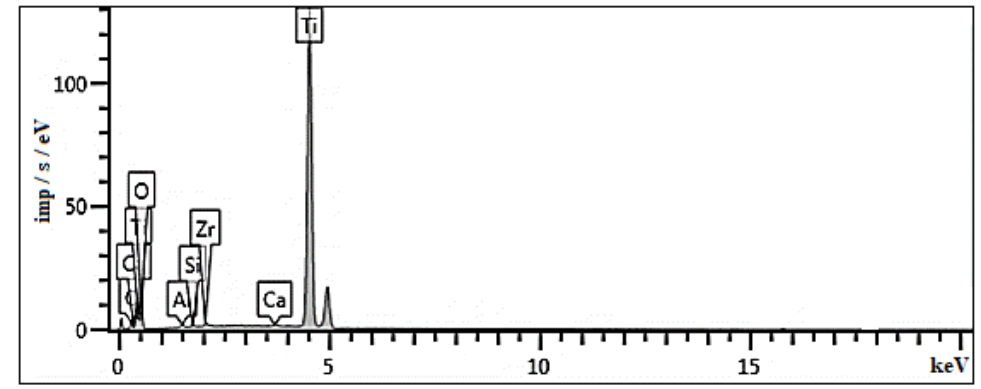

Fig. 3. Spectrogram of a sample of tungsten carbide TiC, obtained in turbulent and laminar flows
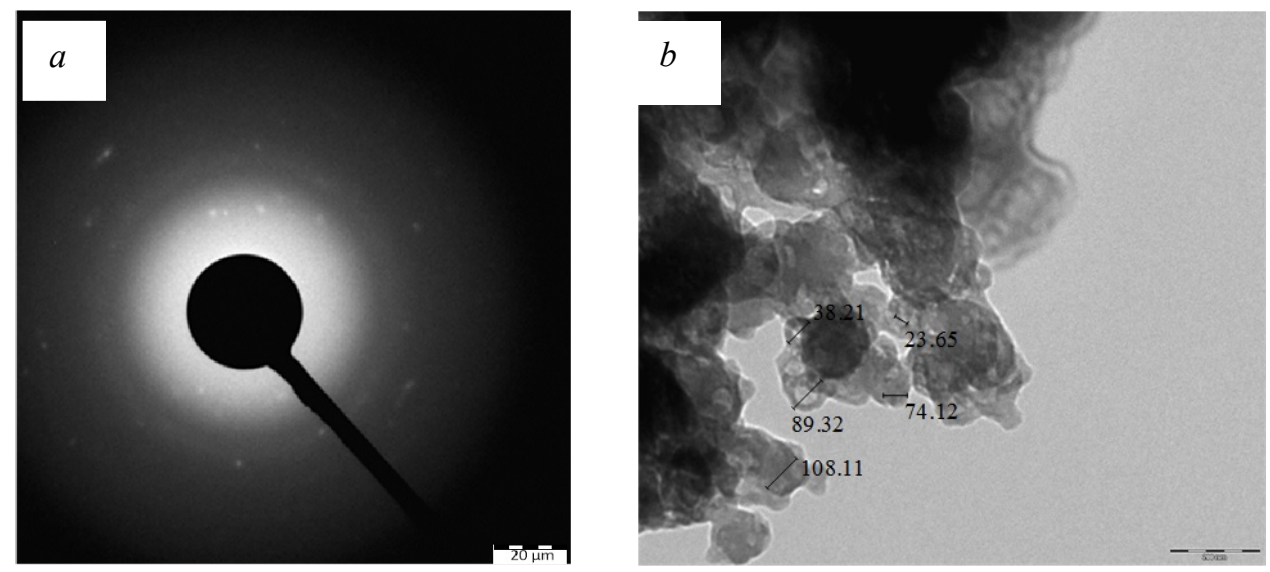

Fig. 4. The image of titanium carbide samples obtained with the transmission electron microscope ZEISS Libra-120, for determining the phase composition: a) the electron diffractogram of the TiC crystal lattice $(20 \mu \mathrm{m}), \mathrm{b}) \mathrm{TiC}$ particles $(200 \mathrm{~nm})$

According to the results of the analysis, the particle sizes in the vapor-drop phase vary from 1 to $150 \mu \mathrm{m}$. (Fig. 5). The phase analysis revealed Ti, TiC phases in various allotropic states. 

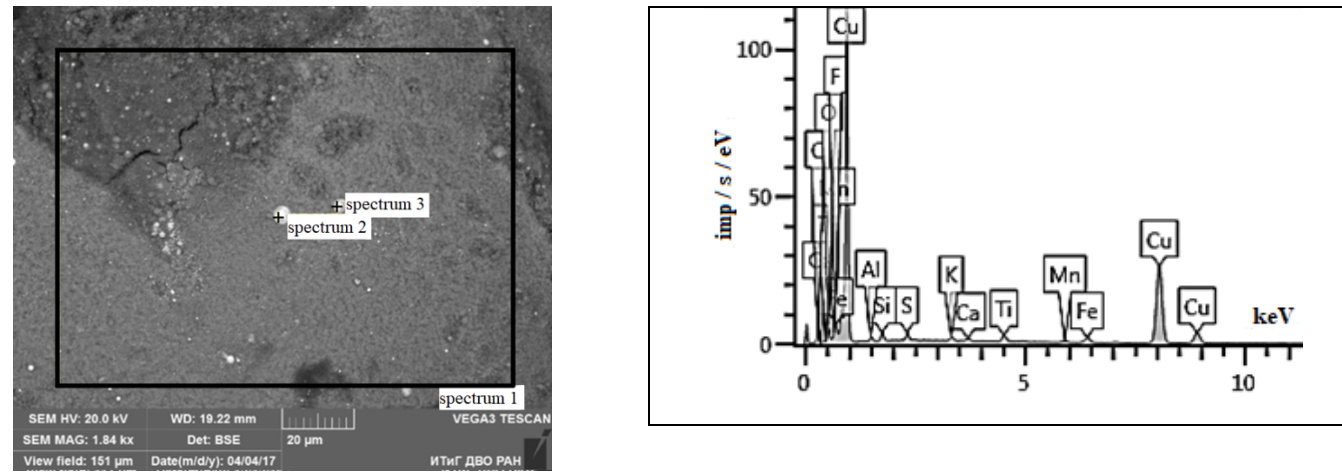

Fig. 5. The image of a vapor-drop phase taken from the chamber walls of the nozzle region and a spectrogram

Chemical analysis also showed the absence of oxygen in the phases, but only under certain conditions for the preparation of samples. In particular, it is necessary to exclude the possibility of prolonged exposure to the atmosphere in the heated state. In the case of atmospheric exposure at $350 \mathrm{~K}$ to $450 \mathrm{~K}$ and higher an oxide component $\left(\mathrm{TiO}_{2}\right)$ was formed on its surface.

The chemical analysis of the vapor-drop phase samples from the nozzle region of the reactor showed the presence of a multitude of associated elements, including Ti.

Table 3. The chemical composition of the samples (Fig. 2. (b)) of the vapor-drop phase resulting from the plasma-chemical synthesis of the powder mixture

\begin{tabular}{|c|c|c|c|c|c|c|c|c|c|c|c|c|}
\hline $\begin{array}{c}\text { Spectr. } \\
\text { No }\end{array}$ & $\mathrm{C}$ & $\mathrm{O}$ & $\mathrm{F}$ & $\mathrm{Al}$ & $\mathrm{Si}$ & $\mathrm{S}$ & $\mathrm{K}$ & $\mathrm{Ca}$ & $\mathrm{Ti}$ & $\mathrm{Mn}$ & $\mathrm{Fe}$ & $\mathrm{Cu}$ \\
\hline $\begin{array}{c}\text { Spectr. } \\
1\end{array}$ & 11.1 & 9.3 & 7.18 & 2.7 & 12.3 & 6.02 & 3.77 & 14.4 & 8.2 & 5.63 & 19.1 & 0.09 \\
\hline Spectr.2 & 12.0 & 12.8 & 8.24 & 3.8 & 11.3 & 9.11 & 2.59 & 13.4 & 4.5 & 4.6 & 16.8 & 0.49 \\
\hline Spectr.3 & 13.1 & 13.7 & 7.93 & 2.6 & 12.1 & 8.02 & 3.01 & 12.6 & 4.9 & 3.34 & 18.0 & 0.37 \\
\hline
\end{tabular}

The absence of a large number of Ti samples is typical for the samples from the nozzle region. In the process of plasma-chemical synthesis, about 0.09 mass $\%$ is deposited from the copper electrode as a result of fracture, and it largely settles on the filter walls, or walls of the reactor in the nozzle region.

\section{Conclusion:}

It has been established that titanium is reduced in the form of titanium carbide, as well as metallic titanium from multicomponent titanium-containing mineral raw materials by the influence of high-density energy with the intensity $g>10^{4}-10^{5} \mathrm{~W} / \mathrm{cm}^{2}$. The technology of $\mathrm{TiC}$ production with the use of plasma-chemical synthesis makes it possible to obtain purity of the final product up to $85.5 \mathrm{wt} \%$.

The use of plasma-chemical synthesis makes it possible to obtain titanium carbide as a high-frequency semi-finished product, with a particle size of 1-150 nm, as a result of a single technological process. With the use of an additional leaching stage, it is possible to obtain $89.5 \mathrm{wt} \% \mathrm{TiC}$ due to the separation during the high-temperature synthesis of all the constituent elements of the charge when they are condensed. 
It is revealed that a high-temperature plasma environment, allows the destruction of the crystal lattice of the mineral, to separate all chemical elements, and to separate Ti from the oxide as well.

The research has shown promising prospects for using high-density energy for the synthesis of refractory compounds from titanium-containing mineral raw materials.

\section{References:}

1. Y.N. Tumanov Plasma, high-frequency, microwave and laser technologies in chemical-metallurgical processes (2010).

2. I.A. Zaks, V.G. Kolesnik, S.G. Melamud, M.V. Malygin, E.V. Urusova, Ferrous metals. 11-12 (2001).

3. V.G. Kolesnik, N.N. Mukhtarova, E.V. Urusova, I. Khidirov, B.S. Iuldashev Nonferrous metals. 12 (2001).

4. T.B. Ershova, N.M. Vlasova, M.A. Teslina, I.A. Astapov Chemical technology. 17 (1) (2016).

5. B.S. Iuldashev, E.V. Urusova Non-ferrous metals. Iss 2 (2003).

6. M.E. Deich Technical gas dynamics.(1961).

7. B.A. Kniazev Low-temperature plasma and gas discharge (2003).

8. K. Madhav Reddy, T.N. Rao, J. Joardar Materials chemistry and physics) 128 (2011).

9. D.V. Onishchenko, V.P. Reva, D.V. Moiseenko Inorganic Materials 48 (11). (2012).

10. U.V. Tsvetkov, A.V. Samokhin, N.V. Alekseev High Energy Chemistry 40 (2). (2006). 